\title{
EVALUATION OF POSTAL DETECTION OF REGISTRABLE BLINDNESS
}

\author{
BY \\ P. A. GRAHAM, F.R.C.S. \\ Consultant Ophthalmologist, United Cardiff Hospitals, and M.R.C. Epidemiological Research Unit \\ J. WALLACE, M.B., Ch.B. \\ Registrar, United Cardiff Hospitals \\ AND \\ E. WELSBY, O.N.D., S.R.N., AND H. J. GRACE, B.Sc. \\ Ophthalmic Technicians, M.R.C. Epidemiological Research Unit, South Wales
}

The registration of persons under the National Assistance Act, 1948, entitles them to the social support of the Welfare Department of the local authority and usually to various statutory and other financial benefits and concessions. Its purpose is primarily social and not statistical. The existence of a list of persons suffering from severely restricted vision and having appended diagnoses has led to the Register becoming a source of national statistics about blindness. As registration is voluntary and the definition of blindness rather vague ("so blind as to be unable to perform any work for which eyesight is essential") the Register is far from ideal for such a purpose. This paper describes a method of ascertaining the prevalence of blindness and a comparison between the results obtained and the register.

\section{TeChNIQUE AND Results}

\section{(a) Population Studied}

All persons aged 65 or over in a large group practice were included in the survey population. In order to limit the population without unduly reducing the number of blind persons, the use of the "65 and over" group which is maintained as a separate list by Executive Councils was adopted, since the prevalence of blindness is thought to rise sharply at about this age. From such a list, made available by the Glamorgan Executive Council, the names of 1,721 persons were obtained after cross-checking with the records of the practice.

\section{(b) Initial Inquiry}

Since the object was to develop a simple inexpensive technique, it was decided that a postal inquiry would offer a likely means of eliminating a large proportion of the population as unlikely to merit direct examination.
A simple questionnaire was compiled, relating vision to everyday activities. This was administered on a trial basis to a series of patients in an ophthalmic clinic, after which some modifications resulted in a revised questionnaire being formulated. In the course of the actual survey, some misunderstandings on the part of recipients led to two further minor modifications. The questionnaire in its final form is given in Appendix A.

Each questionnaire was accompanied by an explanatory letter setting out the aims of the project, together with a pre-paid envelope for its return. If no reply was received within 3 weeks, a second inquiry was sent with a suitable covering letter.

The Figure shows the pattern of response to the postal inquiry. This exceeded expectations, but in retrospect it is clear that the second inquiry could have been sent after 2 instead of 3 weeks, thereby completing the postal aspect of the inquiry within 4 weeks.

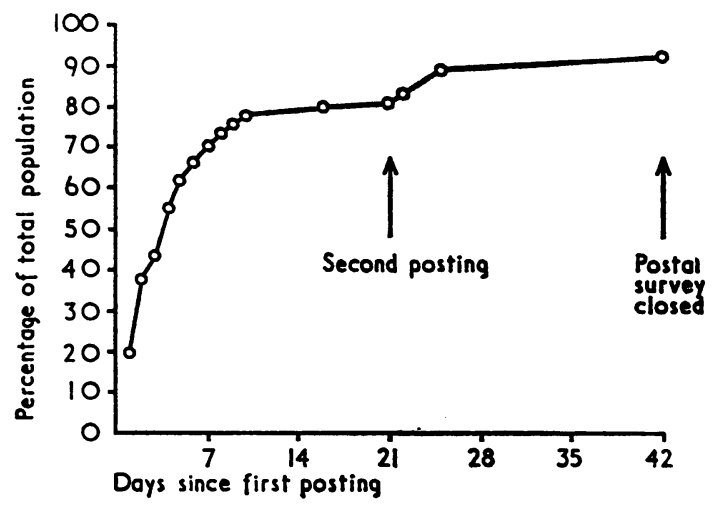

FIGURE.-Response rate to postal survey, three questionnaires combined. 
(c) Analysis of Postal Inquiry and Verification of Results

The immediate results of the postal inquiry are given in Table I, the response rate of 92.5 per cent. of completed questionnaires returned $(1,524$ out of $1,648)$ being highly satisfactory.

TABLE I

RESULTS OF POSTAL SURVEY

\begin{tabular}{l|r|c}
\hline \multicolumn{1}{c|}{ Response } & No. & Per cent. \\
\hline Completed questionnaires returned & 1,524 & $88 \cdot 5$ \\
Under age & 13 & 0.8 \\
Blank and spoilt questionnaires & 46 & $2 \cdot 7$ \\
with or without comments & 138 & 8.0 \\
\hline No reply & 1,721 & 100 \\
\hline Total & & \\
\hline
\end{tabular}

The next step was to score each questionnaire. After some experimentation, the scores shown in Appendix B were adopted. It was hoped that low scores (0-2) would indicate a negligible probability of substandard vision, intermediate scores (3-8) a high probability of substandard vision $(6 / 18$ or less) but negligible prevalence of blindness, and high scores (9-13) a reasonable probability of registrable blindness. In practice it was found that some of the "spoilt" questionnaires did include comments suggesting the existence of a visual defect which in practice would allow their inclusion in a "high" score group, although they have been kept apart for the purpose of this analysis.

After scoring, the population was divided into the three scored groups, and into a "blank or spoilt" questionnaire group, and a "no response" group. All in the "high score" group and all in the "no response" and "blank or spoilt" groups were visited, first by a field survey worker and later if indicated by an ophthalmic technician who made simple estimates of visual acuity and field of vision. In order to check on the accuracy of the postal score as an index of possible blindness, a 1:2 sample of those with intermediate scores (114 persons) and a 1:10 sample of those with low scores were also visited (121 persons).

This visiting enabled three groups to be defined:

(1) Those who were already registered as blind.

(2) Those clearly not likely to be registrable.

(3) Those whom the technician considered might be registrable.

This last group (numbering twenty persons) was reviewed by an ophthalmologist and nine individuals were found to be blind within the meaning of the Act.

The results of the scoring and visiting are summarized in Tables II and III. A fairly high false positive rate results from using high scores as indicating possible blindness, but the elimination of 1,437 of the original corrected population of 1,648 by a simple postal inquiry shows that this procedure is well worth while.

TABLE II

RESULTS OF POSTAL SURVEY AND VISITING

\begin{tabular}{|c|c|c|}
\hline Estimated Population & 1,721 & \\
\hline $\begin{array}{l}\text { Under age } \\
\text { Left area } \\
\text { Dead }\end{array}$ & & \\
\hline Corrected population & 1,648 & \\
\hline $\begin{array}{l}\text { Completed scorable questionnaires } \\
\text { Classified by visiting } \\
\text { III } \\
\text { At sea } \\
\text { No trace }\end{array}$ & $\begin{array}{r}1,524 \\
107 \\
1 \\
1 \\
15\end{array}$ & $\begin{array}{l}92.5 \text { per cent. } \\
6.5 \text { per cent. }\end{array}$ \\
\hline Total & 1,648 & \\
\hline $\begin{array}{l}\text { Percentage of corrected population } \\
\text { covered by postal survey } \\
\text { Percentage of corrected population } \\
\text { covered by postal survey and } \\
\text { interview }\end{array}$ & & $\begin{array}{l}92.5 \text { per cent. } \\
99.0 \text { per cent. }\end{array}$ \\
\hline
\end{tabular}

TABLE III

SCORING RESULTS AND DISTRIBUTION OF BLINDNESS IN CORRECTED POPULATION

\begin{tabular}{|c|c|c|c|c|}
\hline Postal Sub-group & Number & Registered & $\begin{array}{c}\text { Registrable } \\
\text { but not } \\
\text { Registered }\end{array}$ & $\begin{array}{c}\text { Total } \\
\text { Registrable }\end{array}$ \\
\hline $\begin{array}{l}\text { Low score } \\
\text { Intermediate score } \\
\text { High score } \\
\text { Helpful comments } \\
\text { Spoilt/Blank } \\
\text { No reply } \\
\text { No trace } \\
\text { Blank }\end{array}$ & $\begin{array}{r}1,210 \\
227 \\
87 \\
17 \\
25 \\
58 \\
20 \\
4\end{array}$ & $\begin{array}{l}\overline{1 *} \\
18 \\
3 \\
\frac{1}{1} \\
\end{array}$ & $\begin{array}{l}\frac{7}{7} \\
\frac{1}{1} \\
\frac{1}{-}\end{array}$ & $\begin{array}{l}\overline{1 *} \\
25 \\
\frac{4}{2} \\
\frac{2}{-}\end{array}$ \\
\hline Total & 1,648 & 23 & 9 & 32 \\
\hline
\end{tabular}

- The one person who features in the intermediate score range as being registered proved on inquiry to have undergone operation after registration and no longer fulfilled the criteria for registration.

Finally, the Blind Register for the area was checked. This revealed two discrepancies. One was a person with a high postal score whom we had been unable to contact. The second was a man registered as blind with an intermediate score, suggesting that the postal inquiry had failed to indicate suspicion. When this man was examined, however, the postal inquiry proved to be accurate. He had been registered as blind from cataract but had subsequently undergone a successful operation and was no longer registrably blind although his visual acuity was less than normal.

Of those registered or registrable, the postal inquiry indicated 25 out of a total of 32 if only high scores are included, or 29 out of 32 if the "spoilt" forms with helpful comments are included. 
Of the remaining three, two did not reply-one being registered, the other being registrable-and the third returned an intermediate score, as noted in the preceding paragraph. Visiting of the "nonresponders" was therefore relatively unprofitable if the 29 out of 133 with high scores or blank and spoilt forms is compared with two out of 138 apparent "non-responders". There were no confirmed registrable blind in those visited out of the low and intermediate scoring groups.

\section{(d) Comparison of Questionnaires}

It was not possible to make a very accurate comparison between alternative versions, as they were not administered in a random fashion. However, the results are summarized in Table IV, and suggest that Questionnaire III was slightly more confusing to the recipient than I or II, between which there seems little difference.

TABLE IV

COMPARISON OF QUESTIONNAIRES

\begin{tabular}{c|c|c|c|c|c}
\hline \multirow{2}{*}{ Questionnaire } & \multirow{2}{*}{ Number Posted } & \multicolumn{2}{|c|}{ No Reply } & \multicolumn{2}{c}{ Blank or spoilt } \\
\cline { 3 - 6 } & & No. & Per cent. & No. & Per cent. \\
\hline II & 678 & 23 & $(3 \cdot 4)$ & 16 & $(2 \cdot 4)$ \\
III & 371 & 17 & $(4 \cdot 6)$ & 8 & $(2 \cdot 2)$ \\
& 672 & 39 & $(5 \cdot 8)$ & 22 & $(3 \cdot 3)$ \\
\hline
\end{tabular}

\section{Discussion}

The fact that, in this pilot study of a small population, nine out of 31 blind persons were found not to be registered is not surprising, although it is of interest to have this first estimate of coverage. The survey was not undertaken to provide such an estimate, but rather to investigate the accuracy of the technique of postal inquiry and subsequent visiting. This proved to be more successful than we expected. The postal inquiry, with a limited amount of visiting by an ophthalmic technician and even less from an ophthalmologist, produced a surprisingly reliable estimate. In practice, those already registered could be eliminated at the start of the inquiry and it is probable that the loss of accuracy incurred by eliminating apparent "nonresponders", which would halve the number of visits, would not be great.

Although the inquiry was not concerned with the reasons for non-registration of eligible persons, it is of interest to record three impressions gained by the workers in the survey.

(1) Most of those who would benefit appreciably from registration were already on the Register.

(2) Many who were registrable but non-registered were opposed to registration, considering it a form of charity, the acceptance of which was against their principles.

(3) The use of the word "Blind" in the Act is unfortunate.

There is an ominous ring of finality about it which many find distressing. A change to a term such as "Visually disabled" might have psychological advantages; the two grades of the 1948 Act ("Blind" and "Partially sighted") could be labelled aㅇ $\infty$ "Severe visual disability" and "Visual disability" respectively without, necessarily, any change in the actual definitions.

This study resulted from a discussion organized by the Medical Research Council and was financed by a grant from the Ministry of Health to which the authors express their thanks. We should also like to thank Prof. A. L. Cochrane of the Epidemiological Research Unit, Cardiff, for his helpful suggestions, and also Drs A. D. McGill, E. V. A. McGill, I. R. M. McLachlan, V. J. Nash, D. M. J. Williams, and M. V. Williams of Barry, Glamorgan, in whose group practice this study was conducted. 


\section{APPENDIX A}

\section{QUESTIONNAIRE}

NOTE: Please read these questions CAREFULLY and answer by writing "YES" or "NO" on the dotted line at the end of each one. Note that for people who have normal vision the answer is not always "YES".

PLEASE ANSWER ALL THE QUESTIONS, EVEN THOUGH YOU MAY HAVE GOOD VISION

\section{PLEASE USE YOUR GLASSES IF YOU HAVE ANY}

1. Do you have a pair of glasses for reading and close work?

2. If you do not have a pair of reading glasses now, have you ever had a pair prescribed for you?

3. Can you read the small print in a newspaper?

Use your reading glasses

Use your distance glasses
4. Can you thread a needle? (Try, if you are not sure!)

5. Do you have a pair of glasses for distance vision? (NOT dark glasses or "sun glasses").

6. Can you identify coins held in your hand, just by looking at them?

7. Does poor vision make it difficult for you to move around when you are in strange surroundings?

8. When your bus has arrived at the stop, can you read the destination notice on it?

9. Can you recognize your friends when they are on the other side of the road?

If this form was filled in by a friend, please state "YES".

When you have answered all the questions, please put this page into the envelope provided, and post it back to us as soon as you possibly can.

Thank you.

APPENDIX B

Method of scoring Questionnaire

\begin{tabular}{l|c|c|c|c|c|c|c|c|c}
\hline \multicolumn{2}{l|}{ Question } & 1 & 2 & 3 & 4 & 5 & 6 & 7 & 8 \\
\hline \multirow{3}{*}{ Answer } & YES & 1 & - & - & - & - & 2 & - & - \\
& NO & - & - & 3 & 1 & 2 & - & 3 & 1 \\
\hline
\end{tabular}

N.B. In Questionnaire III, question 5 is additional but is a nonscoring question, as also is question 2. 